\title{
Domain I-IV of $\beta 2$-glycoprotein I inhibits advanced glycation end product-induced angiogenesis by down-regulating vascular endothelial growth factor 2 signaling
}

\author{
QIAN-QIAN WANG ${ }^{*}$, SAI-JUN ZHOU* ${ }^{*}$ ZHEN-XING MENG, JIE WANG, \\ RUI CHEN, LIN LV, CHUN-JUN LI, DE-MIN YU and PEI YU \\ 2011 Collaborative Innovation Center of Tianjin for Medical Epigenetics, \\ Key Laboratory of Hormones and Development (Ministry of Health), \\ Metabolic Diseases Hospital and Tianjin Institute of Endocrinology, \\ Tianjin Medical University, Tianjin 300070, P.R. China
}

Received January 31, 2014; Accepted September 9, 2014

DOI: $10.3892 / \mathrm{mmr} .2014 .2970$

\begin{abstract}
Advanced glycation end products (AGEs) are a contributing factor in the angiogenesis that is characteristic of proliferative diabetic retinopathy. However, a previous study made a promising observation that domain I-IV of $\beta 2$-glycoprotein I (DI-IV) inhibits angiogenesis in human umbilical vein cells. The present study aimed to confirm the inhibition of AGE-induced angiogenesis in retinal endothelial cells by DI-IV and to investigate the potential underlying mechanisms. The RF/6A rhesus macaque choroid-retinal vascular endothelial cell line was cultured in vitro and treated with AGEs in the presence or absence of different concentrations of DI-IV. The proliferation, migration and tube formation of the RF/6A cells were evaluated using MTS assays, in vitro wound healing assays and in vitro Matrigel angiogenesis assays, respectively. The mRNA expression of vascular endothelial growth factor (VEGF), VEGF receptor (VEGFR) 2, VEGFR 1 and receptor for AGE (RAGE) were quantified by reverse transcription quantitative polymerase chain reaction. The expression of VEGFR-1, VEGFR-2 and the activation of protein kinase B (Akt) and extracellular signal-regulated kinase (ERK) were also assessed by western blot analysis. The results indicated that AGEs promoted
\end{abstract}

Correspondence to: $\mathrm{Dr} \mathrm{Pei} \mathrm{Yu}$ or $\mathrm{Dr}$ De-Min Yu, 2011 Collaborative Innovation Center of Tianjin for Medical Epigenetics, Key Laboratory of Hormones and Development (Ministry of Health), Metabolic Diseases Hospital and Tianjin Institute of Endocrinology, Tianjin Medical University, 66 Tong'an Road, Heping, Tianjin 300070, P.R. China

E-mail: yupei@tijmu.edu.cn

E-mail: yudemintij@126.com

*Contributed equally

Key words: angiogenesis, domain I-IV of $\beta 2$-glycoprotein I, vascular endothelial growth factor 2 , advanced glycation end products the migration, proliferation and tube formation of RF/6A cells in vitro $(\mathrm{P}<0.05)$, increased the expression of VEGF, VEGFR-2 and RAGE $(\mathrm{P}<0.05)$ and increased the phosphorylation of Akt and ERK $(\mathrm{P}<0.05)$. DI-IV inhibited the increase in VEGFR-2 mRNA and protein, but did not inhibit the increase in VEGF or RAGE mRNAs. These results led to the conclusion that DI-IV inhibited AGE-induced angiogenesis in the RF/6A cells, which was accompanied by a downregulation in the expression of VEGFR-2 and its downstream phosphatidylinosol 3-kinase/Akt and mitogen-activated protein kinase/ERK1/2 pathways. These findings provide further support towards the treatment of proliferative diabetic retinopathy by interventions that act via a mechanism similar to that of DI-IV.

\section{Introduction}

Diabetes mellitus is a serious chronic disease, with an increasing worldwide incidence each year. According to statistics from the World Health Organization, the number of patients with diabetes reached 346,000,000 in 2011 (1). One of the microvascular complications of diabetes, diabetic retinopathy (DR) and, in particular, proliferative diabetic retinopathy (PDR), threatens the vision of patients with diabetes and is the leading cause of blindness among working-age adults (2).

Angiogenesis is the key pathological feature of PDR (3). Advanced glycation end-products (AGEs) are proteins or lipids that are non-enzymatically glycated and oxidized following contact with aldose sugars (4). Animal experiments have revealed that foods rich in AGEs are a risk factor for angiogenesis-associated diseases (5). AGEs promote angiogenesis by increasing the expression of vascular endothelial growth factor (VEGF) in vitro and there is a positive correlation between the levels of AGE and PDR in vivo (6). These findings suggest that AGE are involved in the pathogenesis of PDR.

$\beta 2-$ Glycoprotein I ( $\beta 2-\mathrm{GPI})$, also termed apolipoprotein $\mathrm{H}$, is a phospholipid-binding plasma protein, which consists of five homologous repeated units. $\beta 2-$ GPI is the major autoantigen in patients with antiphospholipid syndrome (7). $\beta 2$-GPI has anti-angiogenetic properties (8) and one of its mutants, in 
which domain $\mathrm{V}$ of domains I-IV is absent (DI-IV), has the potential to produce more marked effects (9).

Our previous study was the first, to the best of our knowledge, to demonstrate that while $\beta 2-$ GPI and DI-IV inhibited angiogenesis in human umbilical vein endothelial cells, DI-IV had a more marked effect (10). Another study found that DI-IV inhibits angiogenesis by downregulating VEGF signaling pathways (11). Therefore, DI-IV may provide a potential treatment for diabetic retinopathy.

The present study investigated whether DI-IV was able to inhibit AGE-induced angiogenesis in $\mathrm{RF} / 6 \mathrm{~A}$ rhesus macaque choroid-retinal vascular endothelial cells and examined the potential mechanisms involved.

\section{Materials and methods}

Materials and reagents. The RF/6A cell line was purchased from the China Center for Type Culture Collection (Wuhan, China). DI-IV was purchased from Tianjin LuoSai Technology Development Co., Ltd. (Tianjin, China) and was produced as previously described (12). AGE-bovine serum albumin (BSA) was purchased from Biovision (Mountain View, CA, USA). Dulbecco's modified Eagle's medium (DMEM) was purchased from Gibco-BRL (Grand Island, NY, USA). Fetal bovine serum (FBS) and pancreatin were purchased from Beijing Solarbio Technology, Ltd. (Beijing, China). CellTiter $96^{\circledR}$ AQueous One Solution regent and Matrigel were purchased from BD Biosciences (Bedford, MA, USA). Monoclonal antibodies to VEGF receptor (VEGFR)-1, VEGFR-2, protein kinase B (Akt), extracellular signal-regulated kinase (ERK), phosphorylated (p)-Akt and p-ERK, anti-mouse immunoglobulin (Ig)G and anti-rabbit IgG labeled with horseradish peroxidase (HRP) were all purchased from Cell Signaling Technology, Inc. (Beverly, MA, USA). All other reagents used were purchased from Sigma (St. Louis, MO, USA).

RF/6A cell culture. The RF/6A cells were cultured in high-glucose DMEM containing 10\% FBS and incubated at $37^{\circ} \mathrm{C}$ in $5 \% \mathrm{CO}_{2}$. The cells were seeded at a density of $5 \times 10^{4}$ cells $/ \mathrm{ml}$ and divided into the following five treatment groups: $100 \mu \mathrm{g} / \mathrm{ml} \mathrm{BSA}$ as a control, $100 \mu \mathrm{g} / \mathrm{ml} \mathrm{AGE}$, $100 \mu \mathrm{g} / \mathrm{ml} \mathrm{AGE}+10 \mathrm{~nm}$ DI-IV, $100 \mu \mathrm{g} / \mathrm{ml}$ AGE+100 nm DI-IV and $100 \mu \mathrm{g} / \mathrm{ml} \mathrm{AGE}+400 \mathrm{~nm}$ DI-IV.

RF/6A proliferation assay. The $\mathrm{RF} / 6 \mathrm{~A}$ cells were seeded onto 96-well tissue culture plates $\left(100 \mu \mathrm{l} /\right.$ well; $5 \times 10^{4}$ cells $\left./ \mathrm{ml}\right)$ and incubated in the regular medium and incubation conditions described above for $24 \mathrm{~h}$ and subsequently with serum-free medium (starved) for $12 \mathrm{~h}$.

Following removal of the growth medium, the cells were incubated for an additional $72 \mathrm{~h}$ in medium supplemented with AGE and/or DI-IV, as described above. Subsequently, $20 \mu \mathrm{l}$ CellTiter $96^{\circledR}$ AQueous One Solution regent, mixed with $100 \mu 1$ growth medium, was added to each well and the cells were incubated at $37^{\circ} \mathrm{C}$ for between 1 and $4 \mathrm{~h}$. The absorbance of each well at $490 \mathrm{~nm}$ was measured using a microplate reader (BioTek Synergy 2; BioTek, Winooski, VT, USA).

In vitro wound healing assay. The $\mathrm{RF} / 6 \mathrm{~A}$ cells were seeded onto 48 -well plates, which were coated with $50 \mu 10.1 \%$ gelatin. When the cells had formed a monolayer, a wound, termed the 'denuded area', was introduced by clearing an area of the monolayer with a micropipette tip. The culture medium in the well was carefully removed and the cells were washed twice with phosphate-buffered saline (PBS) prior to adding medium containing AGE and/or DI-IV, as described previously. After 18-24-h incubation, the cells were washed twice with PBS and fixed with $10 \%$ $(\mathrm{w} / \mathrm{v})$ formalin for $10 \mathrm{~min}$, followed by staining with eosin for $3 \mathrm{~min}$. To determine cell migration into the denuded area (cell number $/ \mathrm{mm}^{2}$ ), images were captured using microscopy with a camera (Leica DM4000 B; Leica Microsystems, Wetzlar, Germany) and analyzed using ImagePro-Plus software (Version 6.0; Media Cybernetics, Inc., Rockville, MD, USA).

In vitro matrigel angiogenesis assay. Briefly, 96-well plates were coated with cold Matrigel (70 $\mu \mathrm{l} /$ well), which was left to polymerize at $37^{\circ} \mathrm{C}$ for $\sim 30 \mathrm{~min}$. Subsequently, $100 \mu \mathrm{l} \mathrm{RF} / 6 \mathrm{~A}$ suspension $\left(5 \times 10^{4}\right.$ cells $\left./ \mathrm{ml}\right)$ was seeded onto the Matrigel and cultured for $24 \mathrm{~h}$ in medium supplemented with AGE and/or DI-IV, as described previously. Tube formation was quantified by determining the mean vessel length in three randomly selected fields using ImagePro-Plus image analysis software.

Analysis of the mRNA expression of VEGF and VEGFR with reverse transcription quantitative polymerase chain reaction (RT-qPCR). The RF/6A cells were seeded and incubated for $24 \mathrm{~h}$, as previously defined. Following culture with serum-free medium overnight, AGE and/or DI-IV were added to the medium. After $48 \mathrm{~h}$ incubation, the total cellular RNA was extracted using TRIzol reagent according to the manufacturer's instructions. The final RNA concentrations were determined by their optical density (OD) at $260 \mathrm{~nm}$ and integrity was verified by ethidium bromide staining of ribosomal $18 \mathrm{~S}$ and $28 \mathrm{~S}$ bands on a $2 \%$ agarose gel. The A260/A280 ratios were between 1.8 and 2.0. The total RNA was then reverse transcribed into cDNA using a SuperScript ${ }^{\mathrm{TM}}$ III Platinum ${ }^{\circledR}$ Two-Step RT-qPCR kit with SYBR ${ }^{\circledR}$ Green. The primers for all the genes asessed were designed using Primer 5.0 software (Premier Biosoft International, Palo Alto, CA, USA). The primer sequences used were as follows: VEGF-A, forward 5'-GCCTTGCACACACTTTGTACTGGT-3' and reverse 5'-TGTCCATAGCTTTCCTCGTGCCT-3'; VEGFR-1, forward 5'-AAGGCCGTGTCATCATTTCCAGAC-3' and reverse 5'-ACCACTTGATTGTAGGTCGAGGGA-3'; VEGFR-2, forward 5'-GCATGTGCTGACGATCATGGAAGT-3' and reverse 5'-ACCACGTGACTCTGCTTCTCCTTT-3'; receptor for AGE(RAGE), forward 5'-TGCTTCTAGAATACAGGCCGGAC A-3' and reverse 5'-TCGGTAGTTGGACTTGGTCTCCTT-3' and $\beta$-actin, forward 5'-ATGAAGTGTGACGTGGACATCCGT-3' and reverse 5'-TCTCCTTCTGCATCCTGTCAGCAA-3'. The PCR cycling conditions on the Rotor-Gene TM 3000 (Corbett Life Sciences, San Francisco, CA, USA) were set as follows: $\mathrm{UCG}$ activation at $50^{\circ} \mathrm{C}$ for $2 \mathrm{~min}$ and $95^{\circ} \mathrm{C}$ for $2 \mathrm{~min}, 45$ cycles at $94^{\circ} \mathrm{C}$ for $5 \mathrm{sec}, 55^{\circ} \mathrm{C}$ for $10 \mathrm{sec}$ and $72^{\circ} \mathrm{C}$ for $10 \mathrm{sec}$. Melting curve analysis was performed between 55 and $95^{\circ} \mathrm{C}$ by monitoring SYBR Green I fluorescence at $0.5^{\circ} \mathrm{C}$ increment increases at $10 \mathrm{sec}$ intervals. All sample measurements were performed in triplicate. $\beta$-actin primers were included to correct for sample-to-sample variation and for each experimental sample, the mRNA levels were normalized to those of $\beta$-actin. 
Western blot analysisfor signaling pathwayanalysis. The RF/6A cells were seeded as previously described, incubated for $24 \mathrm{~h}$ and then cultured with serum-free medium overnight. As mentioned above, cells were divided into five groups. The incubation was terminated by adding $1 \mathrm{ml}$ cold PBS containing $100 \mu \mathrm{M}$ sodium vanadate (Sigma). The samples were then placed on ice, washed with ice-cold PBS and lysed in radioimmunoprecipitation assay buffer containing $50 \mathrm{~mm}$ Tris (pH 7.4), $150 \mathrm{~mm} \mathrm{NaCl}, 1 \%$ Triton X-100, $1 \%$ sodium deoxycholate, $0.1 \%$ SDS, 2 mM sodium pyrophosphate, $25 \mathrm{mM} \beta$-glycerophosphate, $1 \mathrm{mM}$ EDTA, $1 \mathrm{~mm} \mathrm{Na} \mathrm{VO}_{4}$ and $0.5 \mu \mathrm{g} / \mathrm{ml}$ leupeptin. The cells were incubated on ice for $5 \mathrm{~min}$ and were then detached and briefly sonicated. The lysates were clarified by centrifugation $(12,000 \mathrm{xg}, 20 \mathrm{~min}$, $4^{\circ} \mathrm{C}$ ) and the protein content in the supernatant was measured using a Micro BCA ${ }^{\mathrm{TM}}$ Protein kit (Invitrogen Life Technologies, Carlsbad, CA, USA), according to the manufacturer's instructions. Aliquots (30 $\mu \mathrm{g}$ protein/lane) of the total protein were resolved using NuPAGE ${ }^{\mathrm{TM}} 4-12 \%$ Bis-Tris gel and were blotted onto a nitrocellulose transfer membrane. The membrane was inhibited with $2 \%$ BSA in $20 \mathrm{mM}$ Tris- $\mathrm{HCl}$ (pH 7.6), $137 \mathrm{~mm}$ $\mathrm{NaCl}$ and $0.01 \%$ Tween-20 (TBST) for $1 \mathrm{~h}$ at room temperature, followed by incubation with the specific primary antibodies, VEGFR-1, VEGFR-2, p-ERK1/2, total-ERK1/2, Akt and p-Akt (Thr 308). Following washing with TBST, the membrane was reprobed with either HRP-anti-mouse or anti-rabbit IgG $(1: 1,000)$ in $2 \%$ BSA in TBST for $60 \mathrm{~min}$ at room temperature and then exposed to a high-performance chemiluminescence film (Amersham Pharmacia Biotech, Buckinghamshire, UK). The film was developed and densitometry was performed using the Bio-Rad Gel Doc 2000 analysis system (Bio-Rad, Hercules, CA, USA). The relative density of the bands was calculated from the areas under the peaks on plots of OD and compared with that of $\beta$-actin in each sample.

Statistical analysis. Statistical analysis was conducted using SPSS software (SPSS, Inc., Chicago, IL, USA). Values are expressed as the mean \pm standard deviation. An independent sample t-test, one-way analysis of variance and least significant difference-t test were used to evaluate significant differences. $\mathrm{P}<0.05$ was considered to indicate a statistically significant difference. Homogeneity of variance was assessed prior to statistical analysis.

\section{Results}

DI-IV inhibits the AGE-induced proliferation of RF/6A cells. Fig. 1 shows that 3 days of incubation with AGE stimulated the proliferation of $\mathrm{RF} / 6 \mathrm{~A}$ cells $\sim 1.5$-fold $(\mathrm{P}<0.05)$ and that DI-IV inhibited this effect $(\mathrm{P}<0.05)$ at $400 \mathrm{~nm}$.

DI-IV inhibits the AGE-induced migration of RF/6A cells. After 18-24 h incubation with AGE, more cells had migrated into the denuded area. Quantification analysis revealed a 2.5 -fold increase in $\mathrm{RF} / 6 \mathrm{~A}$ cell migration $(\mathrm{P}<0.01)$. DI-IV inhibited this change in a dose-dependent manner $(\mathrm{P}<0.05$; Fig. $2 \mathrm{~A}$ and $\mathrm{B})$.

DI-IV inhibits AGE-induced tube formation in RF/6A cells. AGE induced a 1.7 -fold increase in tube formation in the Matrigel angiogenesis assay. DI-IV inhibited this effect of AGE, however the suppression was only statistically significant

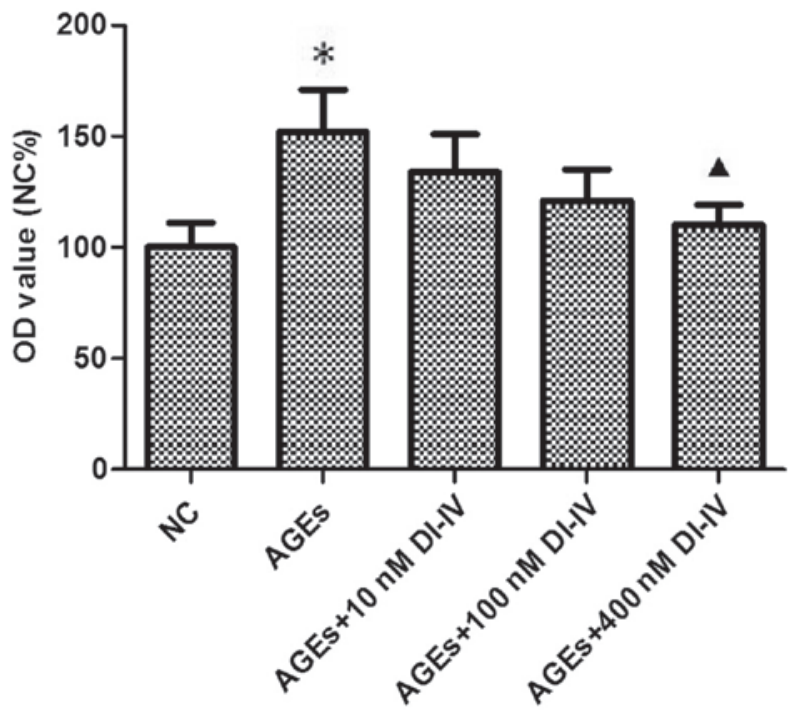

Figure 1. DI-IV inhibits AGE-induced RF/6A proliferation. Cells were incubated with AGE $(100 \mu \mathrm{g} / \mathrm{ml})$ alond or with DI-IV $(10,100$ or $400 \mathrm{~nm})$ for $72 \mathrm{~h}$ and the proliferation was measured following addition of CellTiter $96^{\circledR}$ AQueous One Solution reagent and spectrophotometric quantification. Values are expressed as the mean \pm standard deviation. ${ }^{*} \mathrm{P}<0.05$, compared with the $\mathrm{NC}$ group; ${ }^{\wedge} \mathrm{P}<0.05$, compared with the AGE group. DI-IV, domain I-IV of beta2-glycoprotein I. NC, normal control of RF/6A cells cultured with $100 \mu \mathrm{g} / \mathrm{ml}$ bovine serum albumin; RF/6A, rhesus macaque choroid-retinal vascular endothelial cells; AGE, advanced glycation end products; DI-IV, domain V mutant of $\beta 2$-glycoprotein I.; OD, optical density.

$(\mathrm{P}<0.05)$ at 100 and $400 \mathrm{~nm}$ DI-IV. At these concentrations, the AGE-induced increase in tube formation was eradicated. $(\mathrm{P}<0.05$; Fig. $3 \mathrm{~A}$ and $\mathrm{B})$.

DI-IV inhibits the AGE-induced mRNA expression of $V E G F R-2$. Our previous study identified that DI-IV inhibits human umbilical vein cell angiogenesis through the VEGF pathway (8). To determine whether DI-IV inhibited AGE-induced RF/6A angiogenesis through a similar mechanism, the transcript levels of VEGF and its receptors were measured. Incubation of RF/6A cells with AGE for $48 \mathrm{~h}$ significantly increased the mRNA expression of VEGF, VEGR-2 and RAGE $(\mathrm{P}<0.01$ or $\mathrm{P}<0.05)$. DI-IV inhibited the AGE-induced increase in VEGFR-2 mRNA at DI-IV concentrations of 100 and $400 \mathrm{~nm}$, respectively $(\mathrm{P}<0.05)$, whereas the increases in the mRNA expression of VEGF and RAGE were not inhibited by DI-IV. By contrast, the mRNA expression of VEGFR-1 was not affected by AGE or by DI-IV (Fig. 4).

DI-IV inhibits the expression of VEGFR-2 and the phosphorylation of Akt and ERK1/2 induced by AGE. Incubation of the RF/6A cells with AGE for $48 \mathrm{~h}$ significantly increased the expression of VEGFR-2 and the phosphorylation of Akt and ERK1/2 $(\mathrm{P}<0.05)$; DI-IV inhibited this effect of AGE at concentrations of $100 \mathrm{~nm}$ and $400 \mathrm{~nm}(\mathrm{P}<0.05)$. By contrast, the expression levels of Akt and ERK were not affected by AGE or DI-IV (Fig. 5A-D).

\section{Discussion}

PDR is one of the most severe microvascular complications for diabetic patients and is the major cause of acquired blindness. 
A
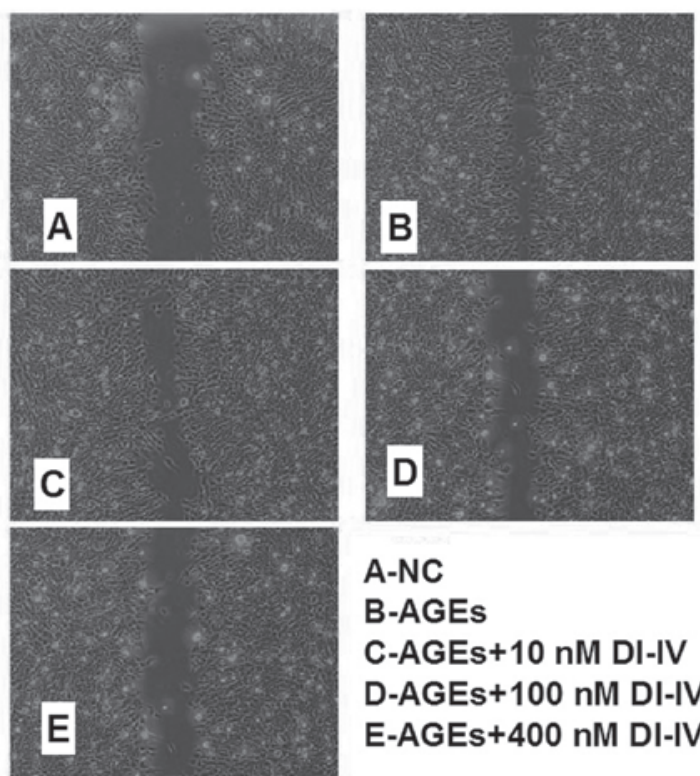

\section{A-NC}

B-AGES

C-AGEs+10 nM DI-IV D-AGEs+100 nM DI-IV E-AGEs+400 nM DI-IV

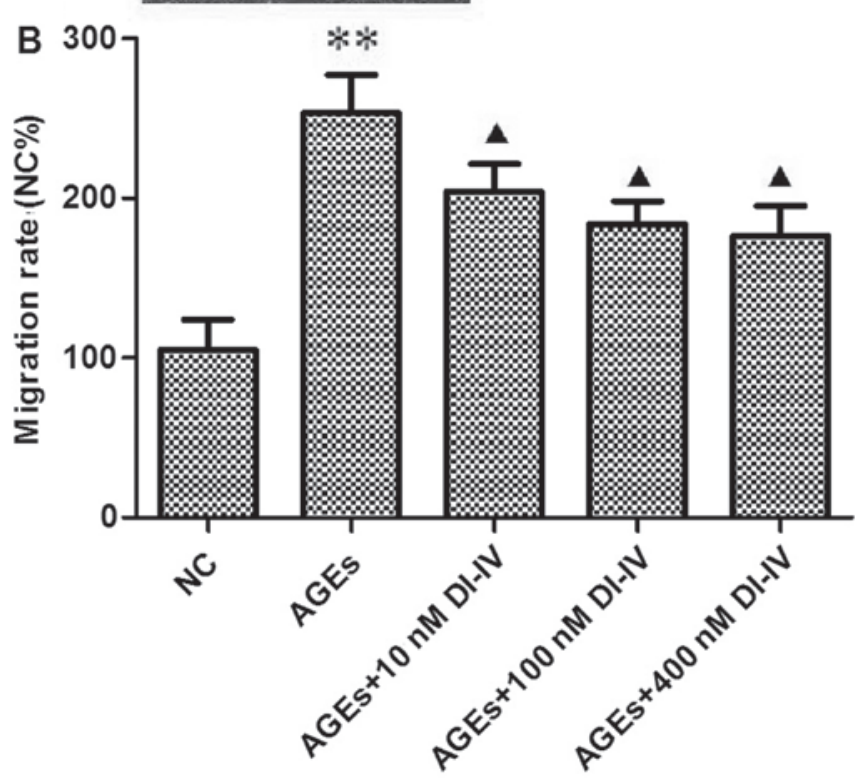

Figure 2. DI-IV inhibits the AGE-induced migration of RF/6A. Confluent monolayers of RF/6A were scraped to remove a section of cells and cultured with control buffer supplemented with AGE $(100 \mu \mathrm{g} / \mathrm{ml})$ alone or with DI-IV $(10,100$ or $400 \mathrm{~nm})$ for $18-24 \mathrm{~h}$. To determine cell migration into the denuded area (cell number $/ \mathrm{mm}^{2}$ ), images were captured and analyzed using ImagePro-Plus software. (A) Representative image of the wound healing assay (Magnification, x40). (B) Migration rate of RF/6A cells compared with the NC. Values are expressed as the mean \pm standard deviation. ${ }^{* *} \mathrm{P}<0.01$, compared with the $\mathrm{NC}$ group; ${ }^{\wedge} \mathrm{P}<0.05$, compared with the AGE group. RF/6A, rhesus macaque choroid-retinal vascular endothelial cells; AGE, advanced glycation end products; NC, normal control of RF/6A cells cultured with $100 \mu \mathrm{g} / \mathrm{ml}$ bovine serum albumin; DI-IV, domain V mutant of $\beta 2$-glycoprotein I.

One important pathogenic mechanism in PDR is neovascularization, which is promoted by various factors, including hypoxia, local inflammation and angiogenic factors, including VEGF and FGF-2 $(13,14)$. VEGF, particularly VEGF-A, is a key factor promoting angiogenesis by binding with its receptors, VEGFR-1 and VEGFR-2. VEGFR-2 has a more dominant role in angiogenesis, while VEGFR-1 is involved mainly in the migration of macrophages and vascular endothelial cells (15). VEGF activates VEGFR and the downstream
A
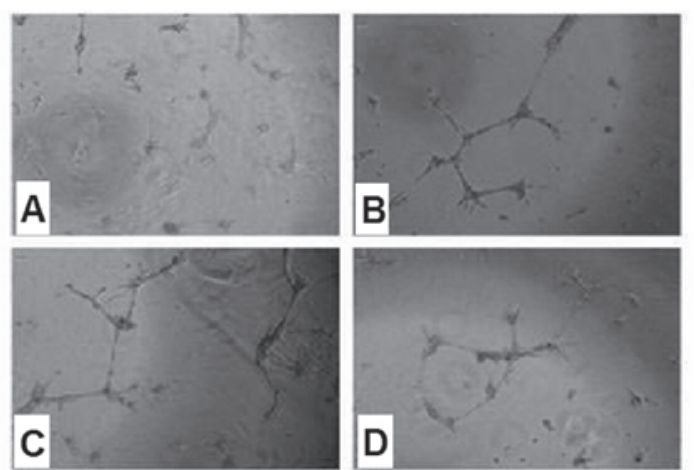

A-NC

B-AGEs

C-AGEs+10 nM DI-IV

D-AGEs+100 nM DI-IV

E-AGEs+400 nM DI-IV

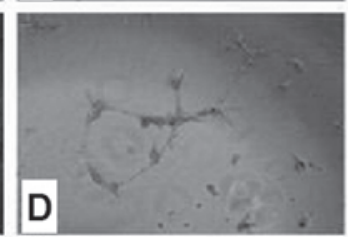

B

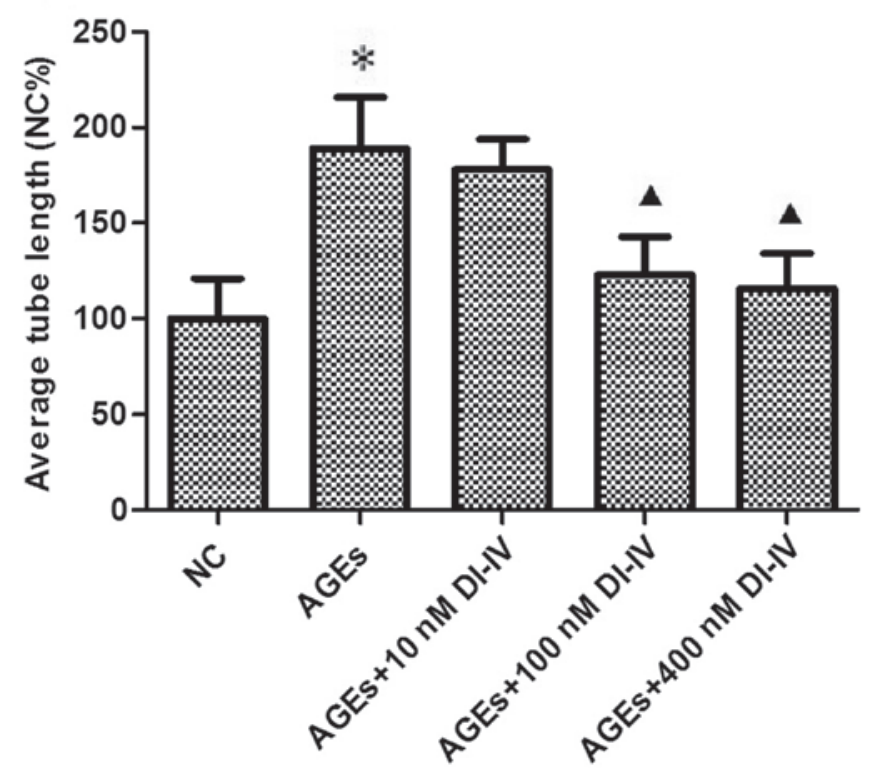

Figure 3. DI-IV inhibits AGE-induced tube formation in RF/6A cells. The $\mathrm{RF} / 6 \mathrm{~A}$ cells were seeded on to the surface of Matrigel-coated wells and cultured in serum-free medium (control) or medium with $100 \mu \mathrm{g} / \mathrm{ml} \mathrm{AGE}$ alone or with DI-IV $(10,100$ or $400 \mathrm{~nm})$. Tube formation was quantified by determining the mean vessel length in three randomly selected fields using the image analysis software, ImagePro-Plus. (A) Representative image (magnification, $\mathrm{x} 40$ ) of RF/6A following $24 \mathrm{~h}$ culture with AGE and DI-IV. (B) Average tube length compared with the normal control. Values are expressed as the mean \pm standard deviation. ${ }^{*} \mathrm{P}<0.05$, compared with the NC group; ${ }^{\wedge} \mathrm{P}<0.05$, compared with AGE group. RF/6A, rhesus macaque choroid-retinal vascular endothelial cells; AGE, advanced glycation end products; NC, normal control of RF/6A cells cultured with $100 \mu \mathrm{g} / \mathrm{ml}$ bovine serum albumin; DI-IV, domain V mutant of $\beta 2$-glycoprotein I.

phosphoinositide 3-kinase (PI3K)/Akt and mitogen-activated protein kinase (MAPK)/ERK1/2 signaling pathways $(16,17)$ and promotes angiogenesis.

$\mathrm{RF} / 6 \mathrm{~A}$ is a long-term culture of a spontaneously transformed endothelial cell line derived from the choroid-retina of the rhesus macaque fetus (18). The morphology, growth, ultrastructure, immunocy tochemistry (immunofluorescence) and immunodiffusion of these cells distinguishes them as endothelial in origin (18). The cells demonstrate prolonged expression of VEGF and VEGFRs (19). Due to their ease of culture and 


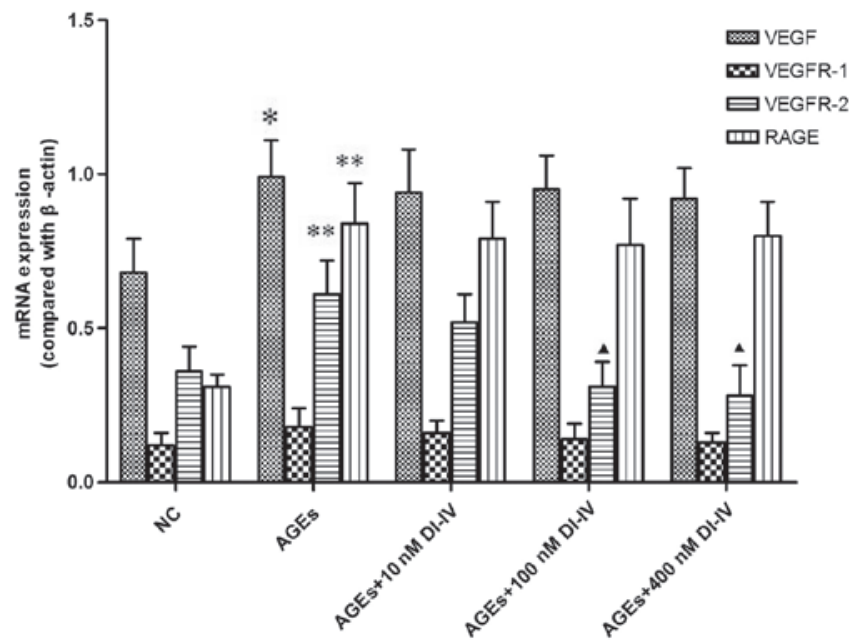

Figure 4. DI-IV inhibits AGE-induced increases in the mRNA expression level of VEGFR-2. The rhesus macaque choroid-retinal vascular endothelial cells were incubated with AGE $(100 \mathrm{~g} / \mathrm{ml})$ alone or with DI-IV $(10,100$ or $400 \mathrm{~nm}$ ) for $48 \mathrm{~h}$. Total cellular RNA was extracted from the cultured cells using TRIzol reagent. The mRNA expression levels of VEGF, VEGFR-2, VEGFR-1 and RAGE were analyzed with reverse transcription quantitative polymerase chain reaction. The mRNA levels were compared with $\beta$-actin. AGE $(100 \mathrm{~g} / \mathrm{ml})$ significantly increased the mRNA expression levels of VEGF, VEGFR-2 and RAGE compared with the NC. DI-IV (100 and $400 \mathrm{~nm}$ ) significantly reduced the AGE-induced increase in the mRNA expression level of VEGFR-2, but not VEGF or RAGE. Values are expressed as the mean \pm standard deviation. ${ }^{*} \mathrm{P}<0.05$ and ${ }^{* *} \mathrm{P}<0.01$, compared with the $\mathrm{NC}$ group; ${ }^{\star} \mathrm{P}<0.05$, compared with the AGE group. AGE, advanced glycation end products; $\mathrm{NC}$, normal control of RF/6A cells cultured with $100 \mu \mathrm{g} /$ $\mathrm{ml}$ bovine serum albumin; DI-IV, domain V mutant of $\beta 2$-glycoprotein I VEGF, vascular endothelial growth factor; VEGFR, VEGF receptor; RAGE, receptor for advanced glycation end products;

rapid transfer, this cell line is widely used in the investigation of PDR and other retina-associated diseases (19-22).

AGE is important in diabetic retinopathy, particularly in PDR $(14,15)$. It is reported that AGE promotes neovascularization by increasing the expression of VEGF (mainly VEGF-A) in endothelial cells and consequently inducing tube formation of the retinal microvessel endothelial cells (23). AGE can potentially induce retinal ganglion cells to express VEGF-A and inhibit apoptosis and are, thus, important in the pathogenesis of diabetic retinopathy (24). The results of the present study revealed that AGE significantly increased the mRNA expression of VEGF and RAGE, promoted the proliferation and migration of vascular endothelial cells and stimulated neovascularization in the $\mathrm{RF} / 6 \mathrm{~A}$ cells. These results led to the hypothesis that AGE promoted the expression of VEGF through interactions with RAGE and was, therefore, important in retinal neovascularization in patients with diabetes mellitus.

The present study demonstrated that AGE significantly increased the expression of VEGF and VEGFR-2 in vascular endothelial cells, however it had no effect on the expression of VEGFR-1. VEGFR-2 is the key receptor regulating VEGF-mediated angiogenesis (25). In the present study, the expression of VEGFR-2 mRNA and protein were examined. The results revealed that the proliferation, migration and tube formation of the RF/6A cells were significantly increased in the AGE group, concomitant with increases in the expression of VEGFR-2 mRNA and VEGFR-2. In the DI-IV treatment group, the proliferation, migration and tube formation of the
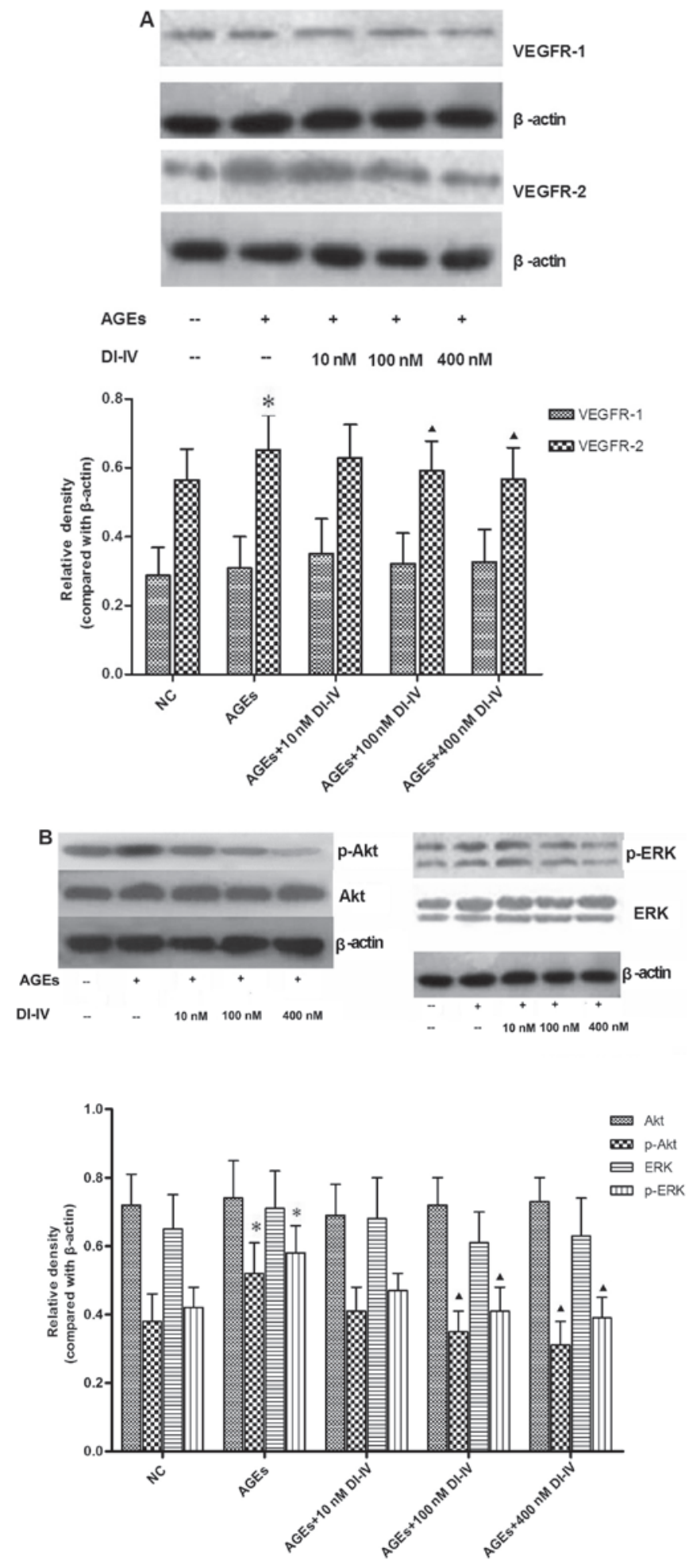

Figure 5. DI-IV inhibits AGE-induced phosphorylation of ERK1/2 and Akt (Thr 308). (A) Representative images and quantitative analyses of VEGFR-1 and VEGFR-2; (B) Representative images and quantitative analyses of p-ERK1/2, total-ERK1/2, Akt and p-Akt. Rhesus macaque choroid-retinal vascular endothelial cells were incubated with AGE $(100 \mathrm{~g} / \mathrm{ml})$ alone or with DI-IV $(10,100$ or $400 \mathrm{~nm}$ ) for $48 \mathrm{~h}$. Total protein was extracted from the cultured cells and protein expression was assessed using western blot analysis. AGE increased the expression of VEGFR-2 and the phosphorylation of Akt (Thr 308) and ERK1/2 compared with the NC. DI-IV inhibited the effect of AGE. By contrast, the expression of Akt and ERK was not affected by AGE or DI-IV. Values are expressed as the mean \pm standard deviation. ${ }^{*} \mathrm{P}<0.05$, compared with the NC group; ${ }^{\wedge} \mathrm{P}<0.05$, compared with the AGEs group; $\boldsymbol{\Lambda}, \mathrm{P}<0.05$. AGE, advanced glycation end products; $\mathrm{NC}$, normal control of $\mathrm{RF} / 6 \mathrm{~A}$ cells cultured with $100 \mu \mathrm{g} / \mathrm{ml}$ bovine serum albumin; DI-IV, domain V mutant of $\beta 2$-glycoprotein I; ERK, extracellular signal-regulated kinase; p-, phosphorlyated. 
RF/6A cells were decreased, as was the expression of VEGFR-2 mRNA and VEGFR-2. Thus, although AGE promoted the expression of VEGF, it also upregulated VEGFR-2 and activated its downstream PI3K/Akt and MAPK/ERK1/2 signaling pathways to inhibit angiogenesis.

Our previous study revealed that DI-IV inhibits human umbilical vein cell angiogenesis by downregulating the expression of VEGFR-2 in endothelial cells and by inhibiting the phosphorylation of VEGF downstream effector molecules in the MAPK/ERK1/2 and PI3K/Akt pathways. Nakagawa et al further identified the potential anti-angiogenic effect of plasmin-nicked $\beta 2$-GPI (26). The findings of the present study demonstrated that DI-IV inhibited the AGE-induced angiogenesis and reduced the AGE-induced cell proliferation and migration. DI-IV also inhibited the dose-dependent AGE-induced increase of VEGFR-2, but not that of VEGF. Since DI-IV also had no effect on the expression of RAGE, the inhibitory effect of DI-IV on AGE-induced angiogenesis must be through the VEGF-A/VEGFR-2 pathway, but not the AGE-RAGE axis. Therefore the present study demonstrated that DI-IV inhibited AGE-induced RF/6A neovascularization by downregulating VEGFR-2 and its downstream effector molecules in the MAPK/ERK1/2 and PI3K/Akt pathways.

In conclusion, AGE promoted neovascularization by binding with RAGE and increasing the expression of VEGF, followed by activation of VEGFR-2 and its downstream PI3K/Akt and MAPK/ERK1/2 pathways. DI-IV had no effect on RAGE or VEGF, however it exerted anti-angiogenic action by downnegulating the expression of VEGFR-2 and its downstream PI3K/Akt and MAPK/ERK1/2 pathways. Therefore, the use of compounds with a similar action to DI-IV provide a potential approach for the treatment of PDR.

\section{Acknowledgements}

The present study was supported by the National Natural Science Foundation of China (nos. 30971393 and 81070645), the Tianjin Natural Science Fund (no. 10JCYBJC12000) and the Science and Technology Fund of Tianjin Health Bureau (nos. 09KZ01 and 2012KG135).

\section{References}

1. Danaei G, Finucane MM, Lu Y, Singh GM, Cowan MJ, Paciorek CJ, et al; Global Burden of Metabolic Risk Factors of Chronic Diseases Collaborating Group (Blood Glucose): National, regional, and global trends in fasting plasma glucose and diabetes prevalence since 1980: systematic analysis of health examination surveys and epidemiological studies with 370 country-years and 2.7 million participants. Lancet 378: 31-40, 2011.

2. Fong DS, Aiello LP, Ferris FL and Klein R: Diabetic Retinopathy. Diabetes Care 27: 2540-2553, 2004.

3. Miller JW, Adamis AP and Aiello LP: Vascular endothelial growth factor in ocular neovascularization and proliferative diabetic retinopathy. Diabetes Metab Rev 13: 37-50, 1997.

4. Goldin A, Beckman JA, Schmidt AM and Creager MA: Advanced glycation end products: sparking the development of diabetic vascular injury. Circulation 114: 597-605, 2006.

5. Sato T, Wu X, Shimogaito N, et al: Effects of high-AGE beverage on RAGE and VEGF expressions in the liver and kidneys. Eur J Nutr 48: 6-11, 2009.
6. Yamagishi S, Matsui T, Nakamura K, et al: Olmesartan blocks advanced glycation end products (AGE)-induced angiogenesis in vitro by suppressing receptor for AGE (RAGE) expression. Microvasc Res 75: 130-134, 2008.

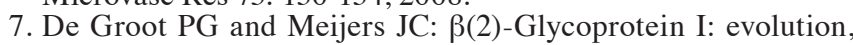
structure and function. J Thromb Haemost 9: 1275-1284, 2011.

8. Passam FH, Qi JC, Tanaka K, Matthaei KI and Krilis SA: In vivo modulation of angiogenesis by beta 2 glycoprotein I. J Autoimmun 35: 232-240, 2010.

9. Yu P, Passam FH, Yu DM, Denyer G and Krilis SA: Beta2-glycoprotein I inhibits vascular endothelial growth factor and basic fibroblast growth factor induced angiogenesis through its amino terminal domain. J Thromb Haemost 6: 1215-1223, 2008.

10. Yu P, Passam FH, Yu DM, Denyer G and Krilis SA: Beta2-glycoprotein I inhibits vascular endothelial growth factor and basic fibroblast growth factor induced angiogenesis through its amino terminal domain. J Thromb Haemost 6: 1215-1223, 2008.

11. Beecken WD, Ringel EM, Babica J, et al: Plasmin-clipped beta (2)-glycoprotein-I inhibits endothelial cell growth by down-regulating cyclin A, B and D1 and up-regulating p21 and p27. Cancer Lett 296: 160-167, 2010.

12. Iverson GM,VictoriaEJandMarquisDM: Anti-beta2-glycoproteinI (beta2-GPI) autoantibodies recognize an epitope on the first domain of beta2-GPI. Proc Natl Acad Sci USA 95: 15542-15546, 1998.

13. Heo JW, Kim JH, Cho CS, et al: Inhibitory activity of bevacizumab to differentiation of retinoblastoma cells. PLoS One 7: e33456, 2012

14. Nichol D and Stuhlmann H: EGFL7: a unique angiogenic signaling factor in vascular development and disease. Blood 119: 1345-1352, 2012.

15. Shibuya M: Tyrosine kinase receptor Flt/VEGFR family: its characterization related to angiogenesis and cancer. Genes Cancer 1: 1119-1123, 2010.

16. Huang Q and Sheibani N: High glucose promotes retinal endothelial cell migration through activation of Src, PI3K/Akt1/eNOS, and ERKs. Am J Physiol Cell Physiol 295: C1647-C1657, 2008

17. Elayappan B, Ravinarayannan H, Pasha SP, Lee KJ and Gurunathan S: PEDF inhibits VEGF- and EPO-induced angiogenesis in retinal endothelial cells through interruption of PI3K/Akt phosphorylation. Angiogenesis 12: 313-324, 2009.

18. Lou DA and Hu FN: Specific antigen and organelle expression of a long-term rhesus endothelial cell line. In Vitro Cell Dev Biol 23: 75-85, 1987.

19. Du W, Yu W, Huang L, Zhao M and Li X: Ephrin-a4 is involved in retinal neovascularization by regulating the VEGF signaling pathway. Invest Ophthalmol Vis Sci 53: 1990-1998, 2012.

20. Amrite AC, Ayalasomayajula SP, Cheruvu NP and Kompella UB: Single periocular injection of celecoxib-PLGA microparticles inhibits diabetes-induced elevations in retinal PGE2, VEGF, and vascular leakage. Invest Ophthalmol Vis Sci 47: 1149-1160, 2006.

21. Sun $\mathrm{T}, \mathrm{Cao} \mathrm{H}, \mathrm{Xu} \mathrm{L}$, et al: Insulin-like growth factor binding protein-related protein 1 mediates VEGF-induced proliferation, migration and tube formation of retinal endothelial cells. Curr Eye Res 36: 341-349, 2011.

22. Grigsby JG, Parvathaneni K, Almanza MA, et al: Effects of tamoxifen versus raloxifene on retinal capillary endothelial cell proliferation. J Ocul Pharmacol Ther 27: 225-233, 2011.

23. Chen P, Zhao J and Gregersen H: Up-regulated expression of advanced glycation end-products and their receptor in the small intestine and colon of diabetic rats. Dig Dis Sci 57: 48-57, 2012.

24. Lee JJ, Hsiao CC, Yang IH, et al: High-mobility group box 1 protein is implicated in advanced glycation end products-induced vascular endothelial growth factor A production in the rat retinal ganglion cell line RGC-5. Mol Vis 18: 838-850, 2012.

25. Shibuya M: Vascular endothelial growth factor (VEGF) and its receptor (VEGFR) dignaling in angiogenesis: A crucial target for anti- and pro-angiogenic therapies. Genes Cancer 2: 1097-1105, 2011.

26. Nakagawa H, Yasuda S, Matsuura E, et al: Nicked \{beta\}2-glycoprotein I binds angiostatin 4.5 (plasminogen kringle 1-5) and attenuates its antiangiogenic property. Blood 114: 2553-2559, 2009. 